\title{
О спектральных характеристиках излучения ядра сейфертовской галактики NGC 7469 в разные эпохи его активности
}

\author{
Л.M. Hapunoвa \\ ФГБУН “Крымская астрофизическая обсерватория РАН”, Научный, Крым, 298409 \\ shali@craocrimea.ru
}

Поступила в редакцию 10 октября 2017 г.

\begin{abstract}
Аннотация. Исследованы важные спектральные характеристики (профили, относительные интенсивности) ярких эмиссионных линий излучения ядра галактики NGC 7469 в разные фазы его активности. На базе наблюдательных данных, полученных на 1.5-м российско-турецком телескопе РТТ-150 в июле 2008 г., и имеющихся публикаций разных исследователей показано состояние активности ядра галактики в эпоху 2008 г. В ноябре 1981 г. имела место активность ядра галактики в форме 6-дневной вспышки.

ABOUT SPECTRAL CHARACTERISTICS OF THE SEYFERT GALAXY NGC 7469 NUCLEUS RADIATION AT DIFFERENT EPOCHS OF ITS ACTIVITY, by L.M. Sharipova. The important spectral characteristics (profiles, relative intensities) of bright emission lines of the Seyfert galaxy NGC 7469 nucleus radiation for different phases of its activity are studied. Observational data obtained at the Russian-Turkish telescope (RTT-150) in July 2008 and publications of different researchers have become the base for showing the state of the galaxy nucleus activity at the epoch of 2008 . The galaxy nucleus activity in the form of 6-day flare took place in November 1981.
\end{abstract}

Ключевые слова: сейфертовские галактики, NGC 7469, переменность эмиссионных линий

\section{1 Введение}

Сейфертовская галактика NGC 7469 - представитель галактик с активными ядрами (АЯГ), предмет постоянного внимания исследователей. Многие работы как отечественных, так и зарубежных авторов посвящены изучению переменности излучения ядра этой галактики на разных шкалах времени. Данная тематика отражена в работах Проник (1975), Де Бруина (1980), Вестина (1984), Чуваева и др. (1990), Розенблатта и др. (1992) и других. Исследования такого характера актуальны - они позволяют выявить эволюционные особенности АЯГ, в частности, вспышечную активность, смену типа ядра галактики и др.

\section{2 Спектральные данные и их обработка}

Наблюдения галактики получены в июле 2008 г. на телескопе РТТ-150 в оптическом диапазоне длин волн 3600-6900 А со спектрометром среднего и низкого разрешения - TFOSC и приемником света - 


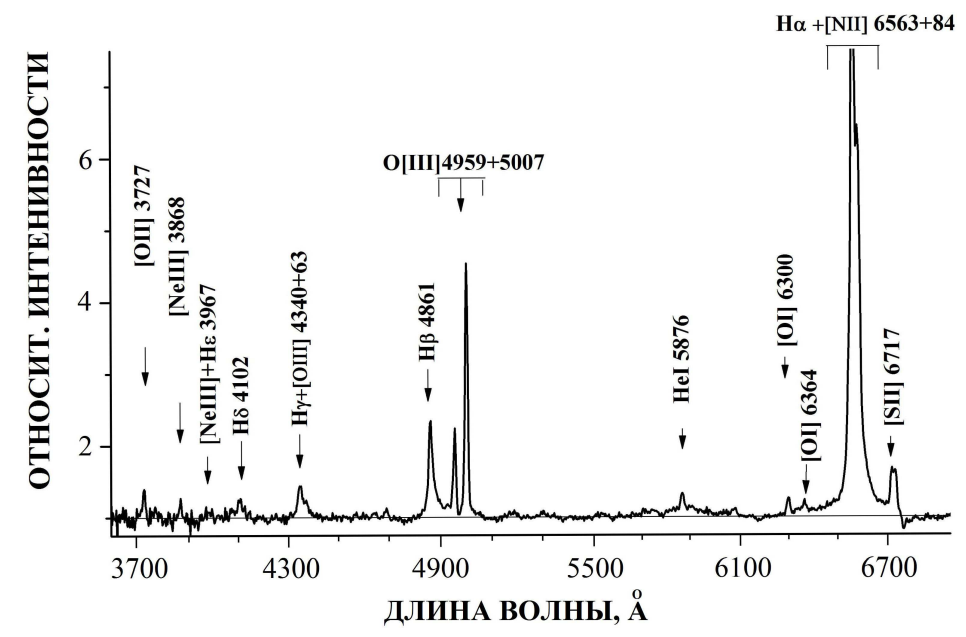

Рис. 1. Спектр галактики NGC 7469, содержащий яркие эмиссионные линии, положение которых отмечено вертикальными стрелками

ПЗС-камерой. Дисперсия, разрешение, щель спектрографа, время экспозиции каждого спектра (на рис. 1 показан пример спектра) составили $1.4 \AA$ Аликс, $7 \AA$, 1" $.8,600$ сек соответственно. Процедуру обработки спектров разработал Г. Галазутдинов ${ }^{1}$.

\section{3 Относительные интенсивности линий серии Бальмера на шкале времени десятилетия}

Были прослежены изменения во времени относительных интенсивностей эмиссионных линий водорода в оптическом спектре ядра галактики. С этой целью использовались спектральные данные, полученные на разных телескопах разными исследователями; публикации последних приведены в квадратных скобках во 2-й строке табл. 1. Фаза яркости ядра указана в 1-й строке таблицы. Условия

Таблица 1. Относительные интенсивности линий серии Бальмера в разные фазы яркости ядра галактики NGC 7469

\begin{tabular}{|c|c|c|c|c|c|c|c|}
\hline яркость ядра & & средняя & мин. & макс. & макс. & мин. & мин. \\
\hline & 2008 & $1986[12]$ & $1976[14,15]$ & $1972[16]$ & $1968[13,15]$ & $1964[16]$ & $1942[17]$ \\
\hline условия & $1.5-\mathrm{m}, 1.8^{\prime \prime}$ & $1-\mathrm{M}, 8^{\prime \prime}$ & $1.25,25^{\prime \prime}$ & $2.6-\mathrm{m}, 2^{\prime \prime}$ & $3-\mathrm{m}, 10^{\prime \prime}$ & $1.25-\mathrm{M}$ & 1.5-M \\
\hline $\begin{array}{l}\text { наблюдений } \\
\lambda(\AA), \text { ион }\end{array}$ & $12 \AA, 3 \AA / п к с$ & $5 \AA$ & $100 \AA$ & $380 \AA ̊ \AA / м м$ & & $140 \AA /$ мм & $195 \AA /$ мм \\
\hline $4101 \mathrm{H}_{\delta}$ & $0.28 \pm 0.01$ & 0.28 & - & 0.55 & 0.30 & 0.30 & 0.35 \\
\hline $4340+63 \mathrm{H}_{\gamma}$ & $0.39 \pm 0.01$ & 0.50 & - & 0.72 & 0.40 & 0.60 & 0.60 \\
\hline $4861 \mathrm{H}_{\beta}$ & 1.00 & 1.00 & 1.00 & 1.00 & 1.00 & 1.00 & 1.00 \\
\hline $6563+84 \mathrm{H}_{\alpha}$ & $5.98 \pm 0.10$ & 4.00 & 3.78 & 11.59 & 4.66 & - & - \\
\hline
\end{tabular}

наблюдений показаны в 3-й и 4-й строках. Относительные интенсивности линий водорода представлены в колонках 2-8. Данные табл. 1 и рис. 1 использовались для анализа изменений во времени относительных интенсивностей бальмеровских линий. Результаты анализа следующие. Относительные

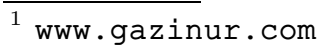


интенсивности линии $\mathrm{H}_{\delta}$ за 44 года (1964-2008 гг.) показали близкие значения. Фактор уменьшения интенсивности линий $\mathrm{H}_{\delta}, \mathrm{H}_{\gamma}, \mathrm{H}_{\alpha}$ за 36 лет (1972-2008 гг.) достигал 2.

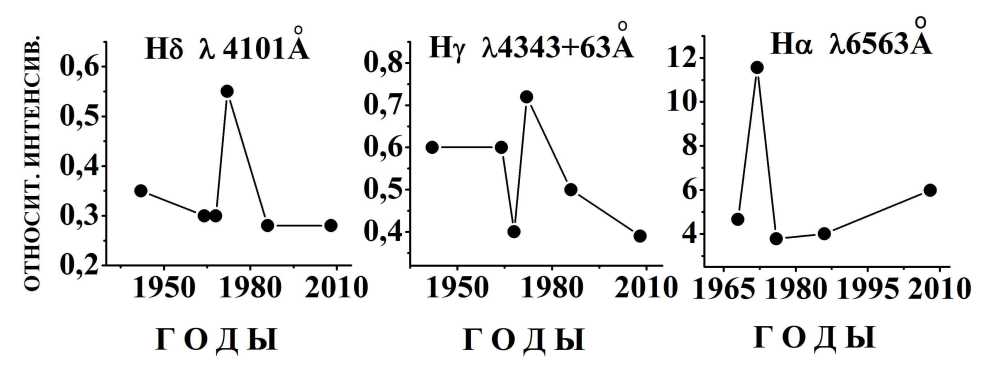

Рис. 2. Вариации относительных интенсивностей водородных линий в спектре ядра галактики на шкале времени десятилетия

На рис. 2 показаны изменения во времени относительных интенсивностей линий $\mathrm{H}_{\delta}, \mathrm{H}_{\gamma}, \mathrm{H}_{\alpha}$ (ось абсцисс). Видно, что характер изменений интенсивностей во времени схожий; при этом бальмеровский декремент крутой и сохраняет переменность на большом интервале времени.

\section{4 Скорости газа в области свечения линии водорода}

Представляло интерес исследовать изменение профиля эмиссионной линии $\mathrm{H}_{\beta}$ во времени. С этой

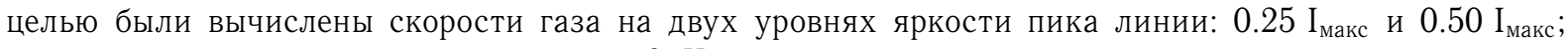
величины скорости газа показаны в табл. 2. Кроме того, проводился сравнительный анализ изменений профиля линии $\mathrm{H}_{\beta}$ на шкале времени около 30 лет с привлечением данных, полученных Розенблаттом и др. (1992).

Таблица 2. Скорости газа в зоне свечения эмиссионной линии водорода в оптическом спектре ядра галактики NGC 7469

\begin{tabular}{lcclcc}
\multicolumn{7}{c}{$\mathrm{H}_{\beta} 4861 \AA$} \\
\hline Дата & $0.25 \mathrm{I}_{\text {макс }}$ & $0.50 \mathrm{I}_{\text {макс }}$ & Дата & $0.25 \mathrm{I}_{\text {макс }}$ & $0.50 \mathrm{I}_{\text {макс }}$ \\
\hline 02.07 .1979 & $3481 \mathrm{kм} /$ сек & $1313 \mathrm{kм} /$ сек & 21.11 .1981 & $3209 \mathrm{kм} /$ сек & $1274 \mathrm{~km} /$ сек \\
22.11 .1979 & 3548 & 1847 & 17.07 .1982 & 3132 & 956 \\
$\mathbf{1 6 . 0 6 . 1 9 8 0}$ & $\mathbf{4 0 2 4}$ & $\mathbf{2 1 4 8}$ & 18.07 .1982 & 3019 & 1073 \\
15.09 .1980 & 3283 & 1576 & 28.09 .1982 & 3120 & 868 \\
03.11 .1981 & 2839 & 1018 & 13.10 .1984 & 3086 & 1247 \\
$\mathbf{1 5 . 1 1 . 1 9 8 1}$ & $\mathbf{1 4 8 1}$ & $\mathbf{5 2 4}$ & $\mathbf{2 9 - 3 1 . 0 7 . 2 0 0 8}$ & $\mathbf{1 3 1 4} \pm \mathbf{2 0}$ & $\mathbf{7 0 5} \pm \mathbf{1 8}$ \\
\hline
\end{tabular}

Эпохи наблюдений показаны в 1-й и 4-й колонках табл. 2. Ширины профиля линии $\mathrm{H}_{\beta}$ на двух уровнях яркости их пика содержатся во 2, 3, 5 и 6-й колонках табл. 2. Экстремальные значения ширины профиля линии $\mathrm{H}_{\beta}$ отмечены наклонным шрифтом. Рост скорости газа в области свечения водорода наблюдался с 1979 г. по 1980 г. Имело место падение скорости газа в этой области

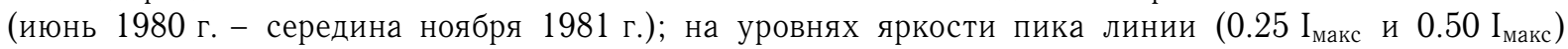
оно было $\sim 3$ и 4 раза соответственно. Отмечен важный наблюдательный факт - 6-дневная вспышка в зоне свечения водорода (15-21 ноября 1981 г.). Скорость газа во время вспышки возросла в 2 раза. Подобная форма активности наблюдалась в галактике NGC 3227(Sy2) (Проник, Метик, 2004; 
Метик и др., 2006). В июле 2008 г. и в ноябре 1981 г. (минимум активности ядра галактики) на

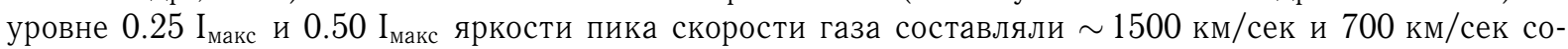
ответственно. Изучение скорости газа в зоне свечения водорода ядра галактики NGC 7469 в эпохи наблюдений 1981 г. и 2008 г. и данные в фильтре V, полученные Дорошенко и др. (1989), свидетельствуют о фазе минимума активности ядра галактики NGC 7469 в 2008 г.

\section{5 Заключение}

Проведенные исследования спектральных характеристик излучения ядра галактики NGC 7469 служат указанием того, что эпоха 2008 г. - фаза минимума активности ядра галактики NGC 7469 . В зоне свечения водорода была 6-дневная вспышка - ноябрь 1981 г.

\section{Литература}

Вестин (Westin B.A.M.) // Astron. Astrophys. 1984. V. 132. P. 136.

Де Бруин (de Bruyn A.G.) // Highlights of Astronomy / Ed. Wayman P.A. Dordrecht: D. Reidel Publ. Company. 1980. V. 5. P. 631.

Дорошенко В.Т., Лютый В.М., Рахимов В.Ю. // Письма в Астрон. журн. 1989. Т. 15. N. 6. Р. 483.

Метик Л.П., Проник И.И., Шарипова Л.М. // Астрофизика. 2006. V. 49. Р. 499.

Проник И.И. // Астрон. журн. 1975. Т. 52. С. 481.

Проник, Метик (Pronik I.I., Metik L.P.) // Astron. Astrophys. Trans. 2004. V. 23. N. 6. P. 509.

Розенблатт и др. (Rosenblatt E.I., et al.) // Astrophys. J. Suppl. Ser. 1992. V. 81. P. 59.

Чуваев и др. // Письма в Астрон. журн. 1990. Т. 16. С. 867. 